\title{
A diamond made microchannel heat sink for high-density heat flux dissipation
}

Yang, Qi; Zhao, Jingquan; Huang, Yanpei; Zhu, Xiaowei; Fu, Weichun; Li, Chengming; Miao, Jianyin

Published in:

Applied Thermal Engineering

Link to article, DOI:

10.1016/j.applthermaleng.2019.113804

Publication date:

2019

Document Version

Peer reviewed version

Link back to DTU Orbit

Citation (APA):

Yang, Q., Zhao, J., Huang, Y., Zhu, X., Fu, W., Li, C., \& Miao, J. (2019). A diamond made microchannel heat sink for high-density heat flux dissipation. Applied Thermal Engineering, 158, [113804].

https://doi.org/10.1016/j.applthermaleng.2019.113804

\section{General rights}

Copyright and moral rights for the publications made accessible in the public portal are retained by the authors and/or other copyright owners and it is a condition of accessing publications that users recognise and abide by the legal requirements associated with these rights.

- Users may download and print one copy of any publication from the public portal for the purpose of private study or research.

- You may not further distribute the material or use it for any profit-making activity or commercial gain

- You may freely distribute the URL identifying the publication in the public portal 


\title{
A diamond made microchannel heat sink for high- density heat flux dissipation
}

\author{
Qi Yang ${ }^{1,2}$, Jingquan Zhao ${ }^{1}$, Yanpei Huang ${ }^{1,2}$, Xiaowei $\mathrm{Zhu}^{3}$, Weichun $\mathrm{Fu}^{2}$, \\ Chengming $\mathrm{Li}^{4}$, Jianyin $\mathrm{Miao}^{2, *}$ \\ 1 School of Aeronautic Science and Engineering, Beihang University, Beijing 100191, PR China \\ 2 Beijing Key Laboratory of Space Thermal Control Technology, Beijing Institute of Spacecraft \\ System Engineering, China Academy of Space Technology, Beijing 100094, PR China \\ 3 Department of Mechanical Engineering, Technical University of Denmark, Nils Koppels Allé, \\ Building 403, 2800 Kongens Lyngby, Denmark \\ 4 Institute of Advanced Materials and Technology, University of Science and Technology Beijing, \\ Beijing 100083, PR China
}

\begin{abstract}
Flow boiling in microchannels is a promising technique for cooling high power-density electronic devices. In this study, a microchannel heat sink using ammonia as working fluid is developed, and its cooling efficiency is experimentally investigated under nonuniform high-density heat flux, which well simulates a practical heat dissipation scenario for microthermal systems. Diamond with high thermal conductivity of $1500 \mathrm{~W} / \mathrm{m} \cdot \mathrm{K}$ is selected as the microchannel heat sink material. A total of 37 parallel triangular microchannels with aspect ratio of 5, channel length of $45 \mathrm{~mm}$ and hydraulic diameter of $280 \mu \mathrm{m}$ are uniformly engineered on the diamond film by laser ablation processing. The significance of diamond substrate as a heat spreader to minimize the nonuniformity of heat flux imposed by a central hotspot is verified. The influences of heat flux and mass flux on the cooling efficiency are experimentally investigated. An optimal range of outlet vapor quality from 0.10 to 0.13 is found, within which the minimum heat source temperature can be achieved. Notably, the microchannel heat sink is capable of managing a central hotspot with heat flux of $267 \mathrm{~W} / \mathrm{cm}^{2}$ while maintaining the heat source temperature at $53.3^{\circ} \mathrm{C}$ for a mass flux of $320 \mathrm{~kg} / \mathrm{m}^{2} \mathrm{~s}$.
\end{abstract}

Keywords: microchannel; flow boiling; ammonia; diamond; hotspot; cooling 
efficiency

\section{Introduction}

Currently, the miniaturization and integration of electronic devices pose new challenges in thermal management. Hotspots have become a critical thermal characteristic of current high power-density electronics, such as central processing units, laser dioxides and insulated gate bipolar transistors, in which the hotspot heat flux can reach $1000 \mathrm{~W} / \mathrm{cm}^{2}$ or higher. Deficient heat dissipation under such a high heat flux will cause excessively high temperature increases, which degrades the device performance and accelerates device failure [1-3]. For high-flux heat dissipation, single/two-phase flow in microchannels, jet impingement, and spray cooling are the most efficient cooling strategies [4]. Agostini et al. [5] performed an extensive literature review comparing various cooling technologies and referred microchannel flow boiling as the most promising technology for high-flux heat dissipation at the moment.

Heat transfer characteristics of flow boiling in microchannels have been studied widely, however there are limited studies conducted under nonuniform heating methods. A theoretical model was developed by Thome and Revellin $[6,7]$ for the critical heat flux (CHF) of flow boiling in microchannels under nonuniform heating conditions. The effects of various parameters on the maximum dissipation rates were investigated numerically. The authors pointed out that a lower number and smaller size of hotspots and a shorter distance between each hotspot are beneficial to heat dissipation under nonuniform heating conditions. Alam and Lee [8] experimentally studied the flow boiling characteristics in a microgap evaporator using a nonuniform heating method. They found that, compared with microchannel heat sink, the utilization of microgap can potentially mitigate local hotspots and achieve better temperature 
uniformity over the heated surface. Ritchey and Garimella $[9,10]$ carried out experiments on the effects of nonuniform heat distribution in a microchannel heat sink mounted directly on an electronic device. The effect of the heating profile on the CHF is found significant in experiments. Placing the hotspot near the outlet can effectively reduce the CHF. In addition, some experimental efforts have explored the flow boiling instabilities [11], flow maldistribution [12, 13], transient behavior of heat transfer $[14,15]$ under nonuniform microchannel heating. These studies provide a basis for understanding the physical mechanism of heat transfer in microchannels under nonuniform heating conditions. However, experiments with nonuniform high heat fluxes are insufficient in these studies.

Table 1

Summary of experimental studies on flow boiling in microchannels.

\begin{tabular}{|c|c|c|c|c|c|c|}
\hline Author & $\begin{array}{l}\text { Microchannel } \\
\text { configuration, } \\
\mu \mathrm{m}\end{array}$ & $\begin{array}{l}\text { Heat sink } \\
\text { material }\end{array}$ & Refrigerant & $\begin{array}{l}\text { Heat } \\
\text { flux, } \\
\mathrm{W} / \mathrm{cm}^{2}\end{array}$ & $\begin{array}{l}\text { Mass } \\
\text { flux, } \\
\mathrm{kg} / \mathrm{m}^{2} \mathrm{~s}\end{array}$ & Heat transfer characteristics \\
\hline Yin et al. [16] & $\begin{array}{l}\text { Rectangular } \\
\mathrm{d}_{\mathrm{h}}: 571\end{array}$ & Copper & $\begin{array}{l}\text { Deionized } \\
\text { water }\end{array}$ & $\begin{array}{l}63.1- \\
98.7\end{array}$ & $\begin{array}{l}261- \\
961\end{array}$ & $\begin{array}{l}\text { Five different flow patterns were observed in turn with increasing } \\
\text { Bo. The HTC mainly depended on heat flux, indicating the dominant } \\
\text { role of nucleate boiling mechanism. The enhancement of heat } \\
\text { transfer by bubble confinement did not work in microchannels with } \\
\text { a large aspect ratio. }\end{array}$ \\
\hline $\begin{array}{l}\text { Markal et al. } \\
{[17]}\end{array}$ & $\begin{array}{l}\text { Rectangular } \\
\mathrm{dh}_{\mathrm{h}}: 100\end{array}$ & Silicon & $\begin{array}{l}\text { Deionized } \\
\text { water }\end{array}$ & $\begin{array}{l}7.1- \\
13.1\end{array}$ & $\begin{array}{l}151- \\
324\end{array}$ & $\begin{array}{l}\text { The wall superheat increased with heat flux, especially for large } \\
\text { aspect ratio microchannels. The HTC increased with increasing AR } \\
\text { until } \mathrm{AR}=3.54 \text {, and then the trend reversed. }\end{array}$ \\
\hline $\begin{array}{l}\text { Hong et al. } \\
{[18]}\end{array}$ & $\begin{array}{l}\text { Rectangular, } \\
\text { parallelogram } \\
\mathrm{d}_{\mathrm{h}}: 1000\end{array}$ & Copper & $\begin{array}{l}\text { Degassed } \\
\text { acetone }\end{array}$ & $\begin{array}{l}0.42- \\
2.09\end{array}$ & $0.3-12.2$ & $\begin{array}{l}\text { Compared with the normal rectangular configuration, the } \\
\text { parallelogram configuration accelerated the outflow of two-phase } \\
\text { flow, reduced the reverse flow, mitigated the flow instability and } \\
\text { enhanced the heat transfer performance by } 8-12 \% \text {. }\end{array}$ \\
\hline Yen et al. [19] & $\begin{array}{l}\text { Circular, square } \\
d_{h}: 210,214\end{array}$ & Pyrex glass & HCFC123 & $\begin{array}{l}2.53- \\
3.92\end{array}$ & $100-800$ & $\begin{array}{l}\text { Corners are effective active nucleation sites and play an important } \\
\text { role in heat transfer characteristics, which is why the square } \\
\text { microchannel acted better than the circular microtube. }\end{array}$ \\
\hline $\begin{array}{l}\text { Daniel et al. } \\
\text { [20] }\end{array}$ & $\begin{array}{l}\text { Circular, square } \\
\text { and triangular } \\
\mathrm{d}_{\mathrm{h}}: 835-1100\end{array}$ & $\begin{array}{l}\text { Stainless } \\
\text { steel }\end{array}$ & $\mathrm{R} 134 \mathrm{a}$ & $1.5-8.5$ & $200-800$ & $\begin{array}{l}\text { For low heat flux, the HTC in circular microchannel was higher, } \\
\text { while for high heat flux, the HTC in triangular microchannel was } \\
\text { higher than that of conventional circular and square microchannels. }\end{array}$ \\
\hline $\begin{array}{l}\text { Korniliou et } \\
\text { al. [21] }\end{array}$ & $\begin{array}{l}\text { Rectangular } \\
\mathrm{d}_{\mathrm{h}}: 192\end{array}$ & $\begin{array}{l}\text { Polydimethy } \\
\text { lsiloxane }\end{array}$ & FC-72 & $\begin{array}{l}1.36- \\
17.92\end{array}$ & $\begin{array}{l}7.37- \\
298\end{array}$ & $\begin{array}{l}\text { The profile of HTC at the microchannel cross section was } \\
\text { nonuniform. The location of maximum HTC moved from the center } \\
\text { to a corner owing to the transition of flow pattern. }\end{array}$ \\
\hline
\end{tabular}




\begin{tabular}{|c|c|c|c|c|c|c|}
\hline $\begin{array}{l}\text { Krishnan et } \\
\text { al. [22] }\end{array}$ & $\begin{array}{l}\text { U-shaped } \\
\text { width: } 305 \\
\text { depth: } 290\end{array}$ & Copper & $\begin{array}{l}\text { Deionized } \\
\text { water }\end{array}$ & $\begin{array}{l}44.1- \\
99.3\end{array}$ & $\begin{array}{l}50-150 \\
\mathrm{ml} / \mathrm{min}\end{array}$ & $\begin{array}{l}\text { The orientation of heating area, especially the vertical with } \\
\text { downflow (VDF) orientation, had a significant influence on the } \\
\text { cooling capacity of microchannel heat sink. While the effect } \\
\text { decreased with increasing mass flux. }\end{array}$ \\
\hline $\begin{array}{l}\text { Fayyadh et al. } \\
\text { [23] }\end{array}$ & $\begin{array}{l}\text { Rectangular } \\
d_{h}: 420\end{array}$ & Copper & $\mathrm{R} 134 \mathrm{a}$ & $\begin{array}{l}1.15- \\
40.3\end{array}$ & $50-300$ & $\begin{array}{l}\text { Bubbly, slug and wavy-annular flow patterns were observed under } \\
\text { different experimental conditions. The HTC rose with heat flux and } \\
\text { was independent of mass flux. }\end{array}$ \\
\hline $\begin{array}{l}\text { Dalkılıç et al. } \\
\text { [24] }\end{array}$ & $\begin{array}{l}\text { Rectangular } \\
\mathrm{d}_{\mathrm{h}}: 421\end{array}$ & Copper & $\mathrm{R} 134 \mathrm{a}$ & $5-46$ & $\begin{array}{l}800- \\
1200\end{array}$ & $\begin{array}{l}\text { The HTC mainly depended on heat flux at low quality region. While } \\
\text { for high quality region, convective boiling began to take control of } \\
\text { the heat transfer, resulting to the increasing HTC with mass flux and } \\
\text { vapor quality until dryout. }\end{array}$ \\
\hline $\begin{array}{l}\text { Thiangtham } \\
\text { et al. [25] }\end{array}$ & $\begin{array}{l}\text { Rectangular } \\
\mathrm{d}_{\mathrm{h}}: 421\end{array}$ & Copper & $\mathrm{R} 134 \mathrm{a}$ & $\begin{array}{l}0.3- \\
12.7\end{array}$ & $150-600$ & $\begin{array}{l}\text { Bubbly flow and slug flow were found at low heat flux region, where } \\
\text { the HTC increased with heat flux. While for high heat flux, wavy- } \\
\text { annular and annular flow were found in microchannels, and the HTC } \\
\text { rose with mass flux. }\end{array}$ \\
\hline
\end{tabular}

Table 1 presents some recent experimental investigations on heat transfer characteristics of flow boiling in microchannels. Microchannels with various types of materials, such as copper, aluminum, stainless steel, silicon and polymer, have been widely studied. Due to the intrinsic thermal conductivity and surface characteristics of different materials, the heat sink material has a certain impact on the heat transfer performance. In addition, previous experiments have revealed that heat transfer characteristics vary drastically with different microchannel configurations. For example, the flow boiling experiments in microchannels performed by Yin et al. [16] disclosed that the enhancement of heat transfer by bubble confinement did not occur in microchannels with a large aspect ratio (AR), which is not the same result as that found in small/medium aspect ratio microchannels. Markal et al. [17] conducted experimental research on the impact of AR on saturated flow boiling in parallel rectangular microchannels. Obtained from the experiments, the wall superheat rose with heat flux, especially for microchannels with a large value of AR. Meanwhile, the heat transfer coefficient (HTC) rose with increasing AR until AR=3.54, and then the trend reversed. Hong 
et al. [18] compared the rectangular configuration and the parallelogram configuration of microchannels in flow boiling experiments. Experimental results showed that the parallelogram configuration accelerated the outflow rate for two-phase flow, and simultaneously reduced the reverse flow, mitigated the flow instability and enhanced the heat transfer performance by $8-12 \%$. Yen et al. [19] carried out flow boiling experiments in microchannels with different cross-sectional geometries but similar hydraulic diameters. Visualization results showed that corners were effective active nucleation sites and played an important role in heat transfer characteristics, contributing to the better performance of square microchannel than that of circular microtube. Daniel et al. [20] conducted flow boiling experiments in circular, square and triangular microchannels with the same perimeter. For high heat flux, the HTC in the triangular microchannel is higher than that of conventional circular and square microchannels. However, flow boiling in triangular microchannels has been rarely studied experimentally. According to a literature review by Tibiriçá et al. [26], only approximately $9 \%$ of studies concerning multi-microchannels were performed for triangular cross sections.

Due to the potential risk of CHF to the safe operation of a heat sink and electronic device, the issue of CHF is an important direction in the study of flow boiling in multi-microchannels. Several experiments were conducted on the triggering mechanism and influencing factors of CHF using different refrigerants. Koşar and Peles [27] performed CHF tests for flow boiling in rectangular multi-microchannels with R123 as the refrigerant. The experimental results showed that CHF increased with mass flux, and there existed an optimum saturation pressure to maximize CHF. From visualization results, dryout was identified as the leading triggering 
mechanism of CHF. Bowers and Mudawar [28] measured CHF of R113 in circular multimicrochannels. The results showed that inlet subcooling had a negligible effect on CHF within their experimental conditions, which is consistent with the results of Qu and Mudawar [29], who used water as a refrigerant in rectangular multi-microchannels. Agostini et al. [30] studied the CHF of R236fa in rectangular multi-microchannels, which revealed that the inlet saturation temperature and inlet subcooling had little effect on CHF. Chen and Garimella [31] conducted experiments on the $\mathrm{CHF}$ of FC-77 for flow boiling in rectangular multi-microchannels, and the results were compared with those of other refrigerants (water, R113). The comparison results implied that the CHF values were closely related to the latent heat of the refrigerant. Park and Thome [32] measured the CHF values of different refrigerants (R134a, R236fa, and R245fa) for flow boiling in rectangular multi-microchannels. At a given mass flux, the CHF of R134a was found to be the largest and that of R236fa was found to be the smallest, which was consistent with the order of the latent heat of these refrigerants. This research indicates the significant influence of the latent heat of refrigerants on flow boiling CHF. Therefore, to avoid the abrupt temperature rise and system failure caused by $\mathrm{CHF}$, refrigerants with larger latent heats are better for cooling high-power-density electronic devices.

Ebadian [4] also pointed out the significant influence of refrigerants on the cooling efficiency of a heat sink. Currently, the refrigerants applied in the microchannel flow boiling research can be roughly sorted into two categories: (1) water [16, 17, 22] and (2) fluorides, such as R134a [20, 23-25], FC-72 [21, 33, 34], HCFC123 [19], HFE-7100 [35, 36], and R246fa $[37,38]$. Water is an ideal refrigerant with a large latent heat, but it is restricted by a narrow operating temperature range. Compared with conventional refrigerants such as fluorides, 
ammonia is known for its high latent heat inferior only to that of water and can operate at cryogenic temperatures, which make ammonia an ideal and efficient refrigerant. However, only a few published researches have studied flow boiling of ammonia in microchannels. Field et al. [39] conducted experiments on pressure drop of two phase flow in a rectangular microchannel $\left(\mathrm{d}_{\mathrm{h}}=148 \mu \mathrm{m}\right)$ utilizing ammonia as working fluid. They found that previous models for pressure drop developed with other refrigerants were unable to accurately predict ammonia flow boiling behavior due to the vastly different fluid properties. Kuang et al. [40] conducted both visualization and measurement studies in which the heat transfer characteristics of ammonia flow boiling were not involved to study the flow boiling instabilities and flow patterns in microchannels $\left(\mathrm{d}_{\mathrm{h}}=1050 \mu \mathrm{m}\right)$. In 2015, Wang and Fang [41] compiled an extensive database of ammonia flow boiling containing 1157 data points to evaluate 37 available correlations. The results showed that the best correlation had a mean deviation of $40.9 \%$, indicating the lack of experimental data and accurate correlations. Accordingly, it is necessary to carry out relevant experimental work to supplement the scarce experimental data for ammonia and understand the internal thermophysical mechanism.

The review above shows that the thermal performance of flow boiling in microchannels depends on many aspects, such as heat sink material, microchannel configuration, refrigerant and heat flux. In this paper, a microchannel heat sink with high cooling performance is developed to manage the high heat load which is generally encountered in electronic devices. The heat sink with parallel triangular microchannels is made of diamond with a high thermal conductivity of $1500 \mathrm{~W} / \mathrm{m} \cdot \mathrm{K}$. Ammonia is used as the refrigerant. Experiments are performed at a saturation temperature of $26^{\circ} \mathrm{C}$, and the mass flux and heat flux are varied between 164 
$1208 \mathrm{~kg} / \mathrm{m}^{2} \mathrm{~s}$ and $71-267 \mathrm{~W} / \mathrm{cm}^{2}$, respectively. The experimental details and the cooling capacity of the heat sink are reported.

\section{Experimental Setup}

\subsection{Flow Loop}

Saturated flow boiling experiments using ammonia as refrigerant are conducted in the closed loop shown in Fig. 1. The main components consist of a reservoir, a centrifugal pump, a plate heat exchanger as a regenerator, a preheater, the test section, a condenser with a water chiller, two sight glasses and two $40 \mu \mathrm{m}$ filters. The reservoir is used to store the working fluid and control system pressure by regulating the ammonia reservoir temperature through a polyimide film heater and a semiconductor chilling plate arranged around the reservoir. Due to the high operating pressure of the ammonia flow boiling experimental system, a safety valve is installed above the reservoir to ensure the operation safety. Downstream of the reservoir, the centrifugal pump is used to circulate the working fluid and regulate the mass flux. To improve the system energy efficiency, the working fluid is first pumped into the plate heat exchanger, where it is preheated by the high temperature fluid from the test section. Then, the working fluid continues to be preheated by the preheater until the desired inlet temperature is reached. Afterwards, the working fluid enters the test section where heat exchange takes place in microchannels. The working fluid finally returns to the reservoir after being cooled by the plate heat exchanger and the condenser. Two sight glasses are separately installed downstream of the test section and condenser to observe the flow condition of the working fluid. The pipes employed in this experiment are all made of stainless steel. In addition, to avoid the impact of the ambient environment on the experiments, the test facility is insulated with high foaming 
polyethylene. A high-speed camera (Phantom V640, Vision Research Inc.) with $1400 \mathrm{f} / \mathrm{s}$ at a full resolution of $2560 \times 1600$ pixels together with a high-magnification lens (EF 24-70mm f/2.8L II USM, Canon Co.) are utilized for flow visualization.

For the data acquisition system, several absolute/differential pressure transducers (WP262-8S1BN-A/0-35 bar, ShangRun Co.) and several PT1000 temperature sensors are placed along the test loop, including two plug-in temperature sensors inserted in the reservoir. Their positions are marked in Fig. 1. An ultrasonic flowmeter (FLUXUS F601, FLEXIM Americas Co.) is placed downstream of the pump to monitor the flow rate. The signals from the transducers and controllers are transmitted by a main control unit (FPXC38ATPLC, Panasonic Inc.) combined with a $2 \mathrm{~kW}$ DC switching power supply and several solid-state relays. MCGS monitoring software is employed to monitor and record the measured parameters in real time. 


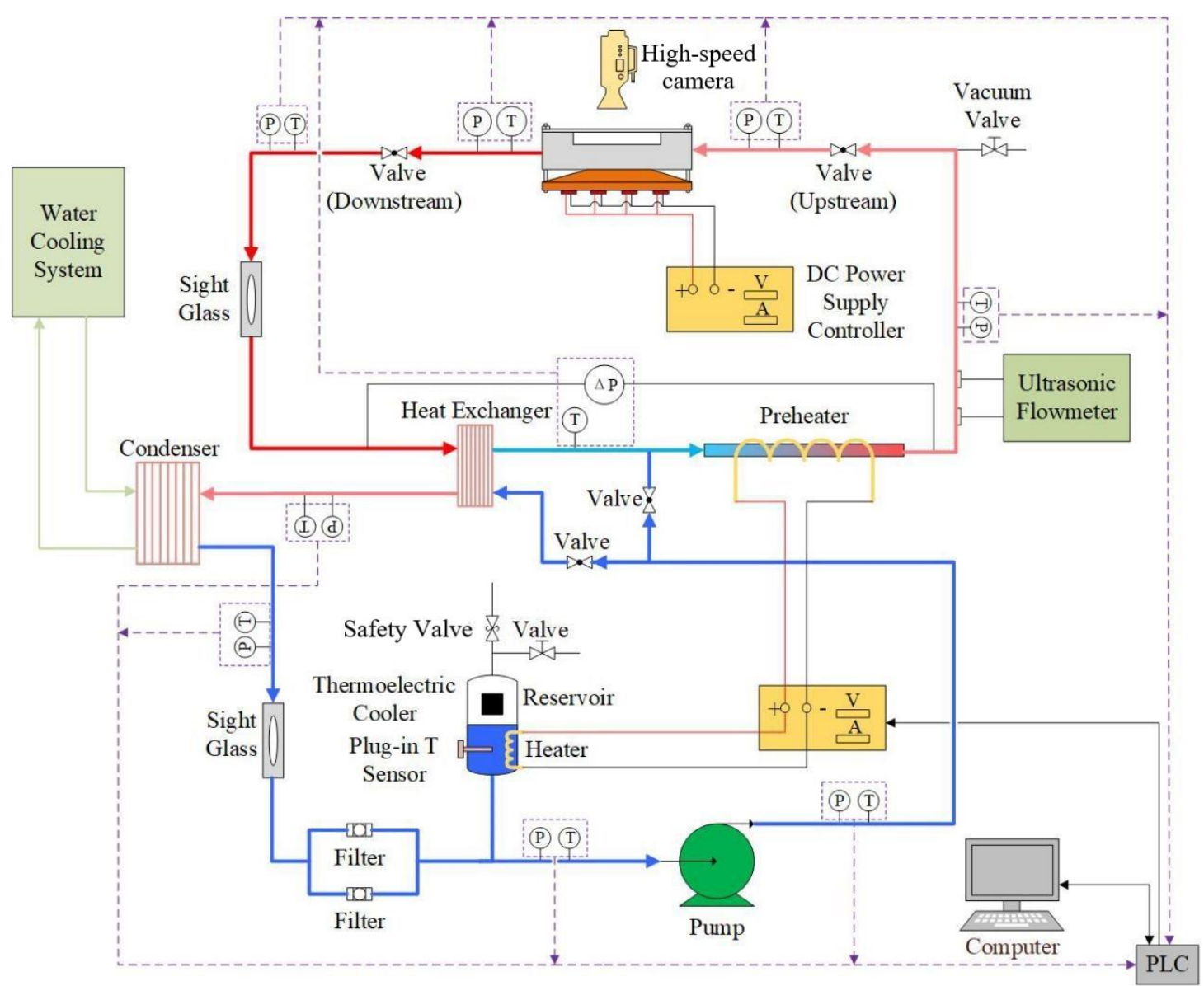

Fig. 1. Schematic diagram of the flow boiling test loop.

\subsection{Test Section}

Fig. 2 shows the configuration of the test section, wherein the microchannel heat sink is placed. The evaporator designed in this study consists of a diamond microchannel heat sink (d), Mo-Nb alloy shell (b, e) and transparent sapphire window (c), all of which are welded together by vacuum brazing technology to strictly seal the high-pressure ammonia, consequently the leakage rate is determined to be less than $3.0 \times 10^{-10} \mathrm{~Pa} \cdot \mathrm{m}^{3} / \mathrm{s}$ as detected by helium mass spectrometry. The heat load is fed by the copper block. If more than $25 \mathrm{~W} / \mathrm{cm}^{2}$ heat flux is directly supplied by ceramic heaters, the high heat source temperature may damage the heaters. For this consideration, we design a copper block (g) as a medium for transferring heat from the heaters to the heat sink which has a large bottom area $\left(80 \times 80 \mathrm{~mm}^{2}\right)$ but a small upper surface area $\left(25 \times 6 \mathrm{~mm}^{2}\right)$, namely, the directly heated area. Four $40 \times 20 \mathrm{~mm}^{2}$ ceramic 
heaters (h) are bonded to the bottom of the copper block using silicone rubber (GD414) to fix their positions, and Ga-In alloy liquid metal (K-ZOON TG-2 type) is used as the interfacial filler to minimize the thermal contact resistance. The heaters are powered by a DC power supply (Agilent 6675A DC, Agilent Technologies Inc.) with adjustable voltage of 0-120 V and current of $0-18 \mathrm{~A}$. As the heat conduction area decreases along the direction of heat flow, the heat conducted from the ceramic heaters to the heat sink becomes more and more intense along the heat flow direction and finally gathers on the upper surface. The upper surface of the copper block is directly attached to the base surface of the heat sink $\left(45 \times 22.5 \mathrm{~mm}^{2}\right)$, which well mimics the practical heat dissipation scenario with nonuniform high heat flux. The interface is also filled with Ga-In alloy liquid metal. With the special design of the copper block, this study can obtain high-density heat flux up to $267 \mathrm{~W} / \mathrm{cm}^{2}$ on the directly heated area without damaging the ceramic heaters. The evaporator, copper block and ceramic heaters are assembled together and placed in a thermal insulated box (i) to prevent heat loss to the ambient. The thermal conductivity of the high foaming polyethylene wrapped around the box is less than $0.034 \mathrm{~W} / \mathrm{m} \cdot \mathrm{K}$. Quartz glass (a) covers the top of the test section to give a window for visualization. The high-speed camera is then placed in front of the window to record the flow pattern during evaporation. 


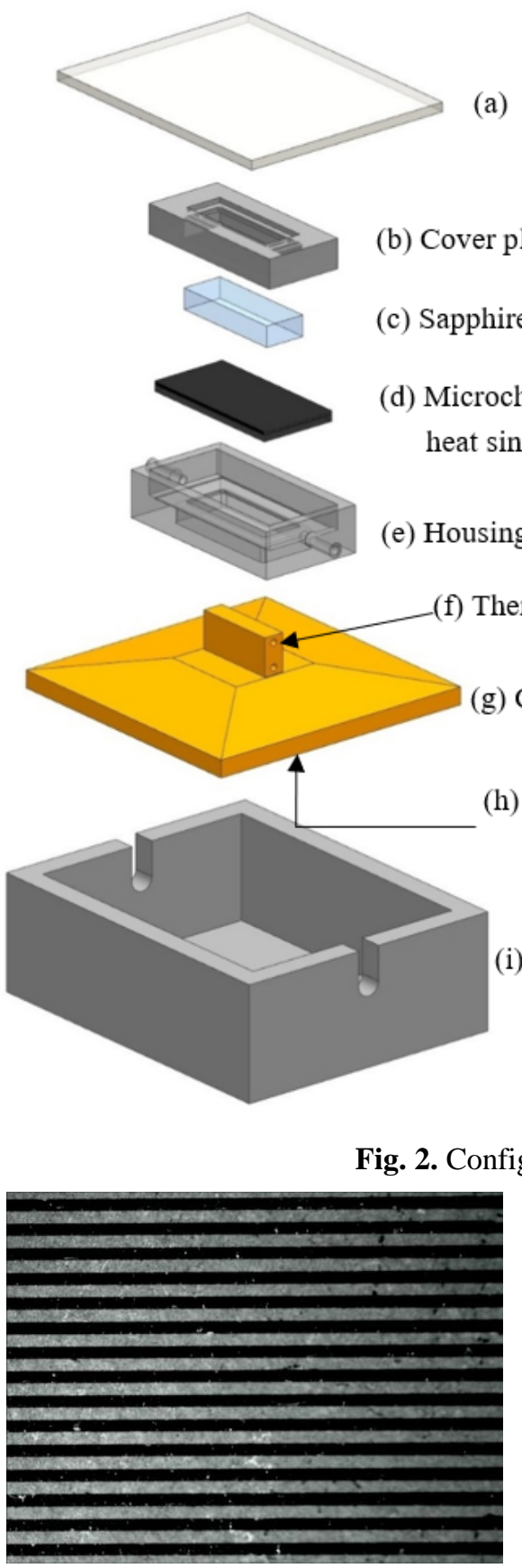

(a)

(a) Quartz glass

(b) Cover plate

(c) Sapphire

(d) Microchannel heat sink
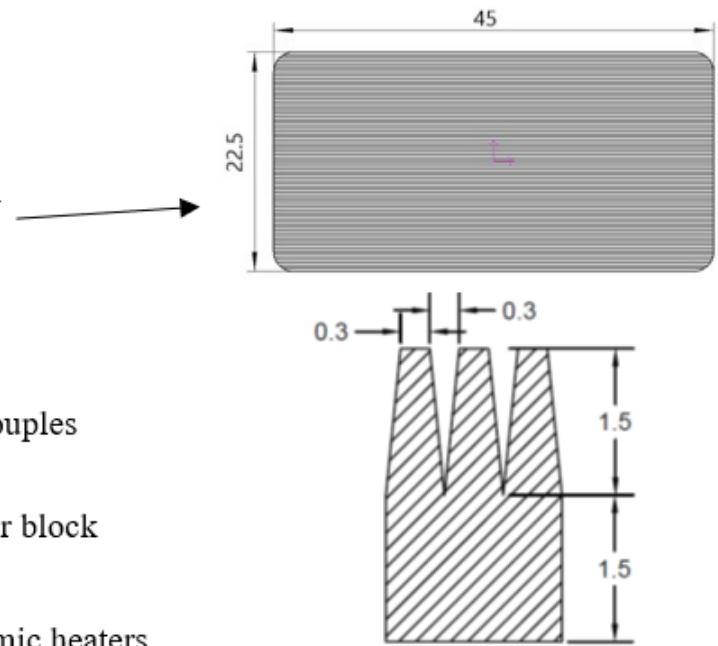

h) Ceramic heaters

(on the bottom)

(i)Thermal insulated box

Fig. 3. Shape of the microchannels from (a) top view and (b) cross-section view.

The heat sink is fabricated on a polycrystalline diamond film that is obtained by the DC arc plasma jet chemical vapor deposition method (DC PJ CVD). Due to the extremely high rigidity and abrasion resistance of diamond, it is difficult to process microchannels on diamond films by common mechanical machining methods. However, as a noncontact and efficient machining method, laser machining can achieve high machining precision without breaking 
the fragile material and is proven to be very suitable for processing microchannels on diamond films. Thus the laser ablation processing method is used in this study to manufacture triangular microchannels on diamond films. The microchannel configuration is presented on the right side of Fig. 2. As shown, 37 parallel triangular microchannels are uniformly shaped on the diamond film with overall dimensions of $45 \mathrm{~mm}$ length, $22.5 \mathrm{~mm}$ width and $3 \mathrm{~mm}$ thickness. Each triangular microchannel has a depth of $1500 \mu \mathrm{m}$ and a width of $300 \mu \mathrm{m}\left(\mathrm{d}_{\mathrm{h}}=280 \mu \mathrm{m}\right)$. The real shape of the microchannels is shown in Fig. 3. Table 2 lists the physical properties of the diamond heat sink. Notably, the thermal conductivity of diamond is not less than 1500 $\mathrm{W} / \mathrm{m} \cdot \mathrm{K}$. The surface roughness is an important parameter for characterizing flow boiling, particularly for the microchannels. Prior to the experiment, the inner wall of the microchannels is observed with a ZEISS EVO18 scanning electron microscope (500x), and the observed image is shown in Fig. (a). The surface roughness (Ra) of the microchannel inner wall is 2027 $\mathrm{nm}$ as measured by a DEKTAK150 surface profiler, and the distribution results are depicted in Fig. (b).

Table 2

Physical properties of the diamond heat sink.

\begin{tabular}{ll}
\hline Parameter & Diamond heat sink \\
\hline Friction coefficient & 0.1 \\
Thermal expansion coefficient $\left(\times 10^{\left.-6 /{ }^{\circ} \mathrm{C}\right)}\right.$ & 2.0 \\
Thermal conductivity $(\mathrm{W} / \mathrm{m} \cdot \mathrm{K})$ & $\geq 1500$ \\
Specific heat $(\mathrm{J} / \mathrm{g} \cdot \mathrm{K})$ & 0.540 \\
Electrical resistivity $(\Omega \cdot \mathrm{cm})$ & $10^{12}$ \\
\hline
\end{tabular}




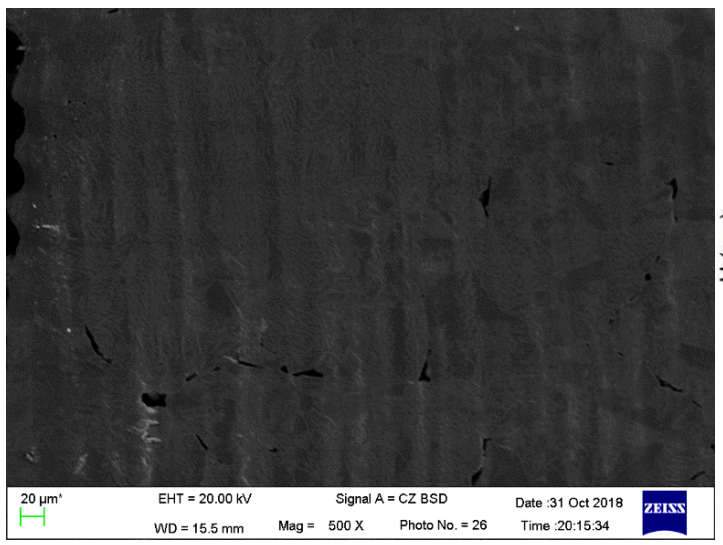

(a)

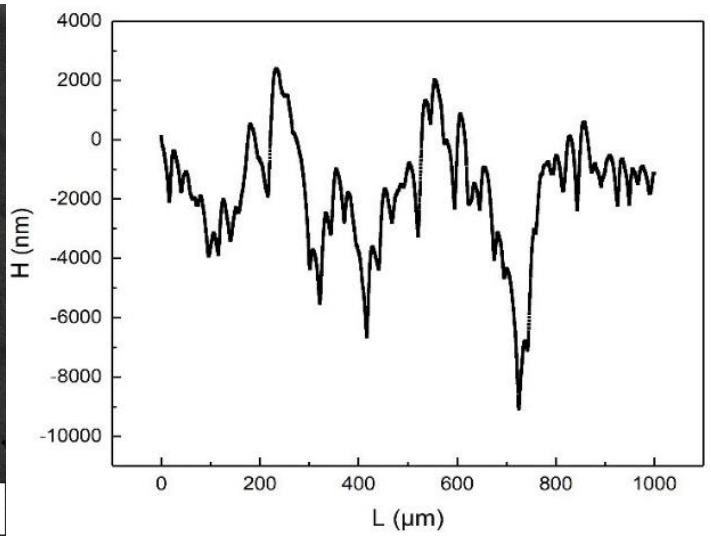

(b)

Fig. 4. Surface roughness of the microchannel inner wall, (a) microscope morphology of the surface and (b) the qualitative measurement of the surface roughness.

As shown in Fig. (a), two pairs of holes are drilled into the copper block with an interval of $7 \mathrm{~mm}$ between the two holes on the same side. Four copper-constantan T-type thermocouples $\left(\mathrm{T}_{3}-\mathrm{T}_{6}\right)$ are separately installed in these holes to accurately obtain the temperature gradient as well as the upper surface temperature of the copper block, which is referred to as the heat source temperature $T_{h}$. Two thermocouples $\left(T_{i n}, T_{\text {out }}\right)$ are placed separately at the inlet/outlet stainless steel tubes of the evaporator to measure the fluid temperature. As marked in Fig. (b), two thermocouples $\left(\mathrm{T}_{1}, \mathrm{~T}_{2}\right)$ are placed adjacent to the directly heated area, and the coordinates of their locations are $\mathrm{z}=-13.5 \mathrm{~mm}\left(\mathrm{~T}_{1}\right)$ and $\mathrm{z}=+13.5 \mathrm{~mm}\left(\mathrm{~T}_{2}\right)$. The $\mathrm{Z}$-axis is aligned with the flow direction, and the coordinate origin is set at the midpoint of the direction heating area. All the thermocouples mentioned above are connected to a data acquisition unit (Agilent 34970A, Agilent Technologies Inc.). Agilent BenchLink Data Logger 3 software is employed to monitor and record the measured temperature data in real time. 


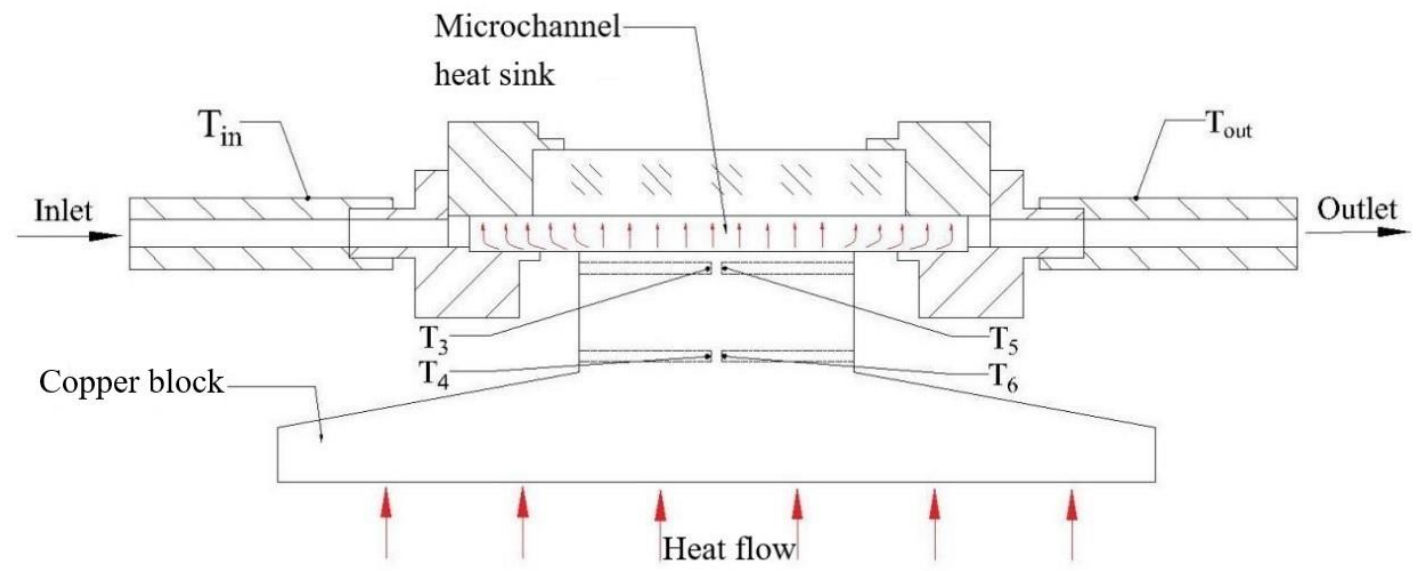

(a)

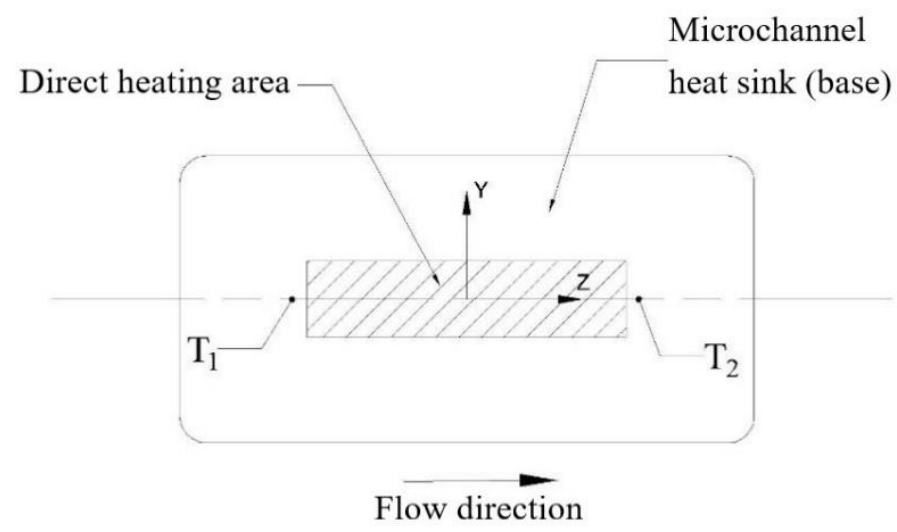

(b)

Fig. 5. Schematic diagram of the heat transfer direction and thermocouple distribution.

\section{Data Reduction and Uncertainty Analysis}

\subsection{Data Reduction}

The heat power supplied by the DC power source to the ceramic heaters, $Q$, can be simply obtained by electrical current multiplied by voltage, and these values are displayed by the screen of power source.

$$
Q=U I
$$

Considering the high temperature of the copper block when transferring heat from heater to heat sink, the heat loss to the ambient needs to be evaluated. The heat power delivered to the working fluid is experimentally evaluated in single-phase experiments and is approximately equal to the effective heat power, $Q_{\text {eff }}$, calculated from the measured temperature gradient by Eqs. (3) and (4). The heat loss to the ambient, $Q_{\text {loss }}$, is determined to be approximately $6 \%$ 
under the experimental conditions.

$$
\begin{gathered}
Q=Q_{\text {eff }}+Q_{\text {loss }} \\
Q_{\text {eff }}=k_{C u} A_{C u} \frac{\Delta T}{\Delta x} \\
\Delta T=\left[\left(T_{4}+T_{6}\right)-\left(T_{3}+T_{5}\right)\right] / 2
\end{gathered}
$$

where $A_{C u}$ is the upper surface area of the copper block, i.e. the directly heated area, $k_{C u}$ is the thermal conductivity of copper, $\Delta T$ is the temperature gradient, $T_{3} \sim T_{6}$ are the measured temperatures at different locations as shown in Fig. (a), and $\Delta x$ is the vertical interval between the locations of $T_{3}$ and $T_{4}$ as well as $T_{5}$ and $T_{6}$.

The imposed heat flux referred to the directly heated area, $q$, is written as:

$$
q=\frac{Q_{e f f}}{A_{C u}}
$$

For saturated flow boiling experiments, the outlet vapor quality $x_{e}$ can be obtained based on the energy balance:

$$
x_{e}=\frac{Q_{e f f}-c_{p, l} \cdot \dot{m} \cdot\left(T_{o u t}-T_{\text {in }}\right)}{\gamma \dot{m}}
$$

where $\dot{m}, c_{p, l}$ and $\gamma$ represent the mass flow rate, specific heat capacity and latent heat of ammonia, respectively.

Along the heat conduction direction, $T_{h}$ and $T_{b}$ can be obtained by Eqs. (7) and (8) on the basis of the one-dimensional heat conduction. The heat source temperature, $T_{h}$, refers to the temperature of the upper surface of the copper block. $T_{b}$ denotes the temperature at the midpoint of the directly heated area on the heat sink base surface.

$$
\begin{gathered}
T_{h}=\frac{T_{3}+T_{5}}{2}-\frac{Q_{e f f} l_{t}}{k_{C u} A_{C u}} \\
T_{b}=T_{h}-\frac{Q_{e f f}}{h_{0} A_{C u}}
\end{gathered}
$$

where $T_{\text {in }}$ and $T_{\text {out }}$ are the temperatures of the working fluid at the inlet and outlet of the heat sink, respectively, $h_{0}$ is the equivalent contact HTC of the liquid metal and its value is determined as $214700 \mathrm{~W} / \mathrm{m}^{2} \mathrm{~K}$ based on the measurement results of the thermal resistance measuring instrument, $l_{t}$ is the normal distance between the thermocouples $\left(\mathrm{T}_{3}, \mathrm{~T}_{5}\right)$ and the 
upper surface of the copper block and $k_{c}$ is the thermal conductivity of diamond.

\subsection{Uncertainty Analysis}

A brief uncertainty analysis is conducted for both the primary and calculated parameters listed in Table 3. For all the measured variables, the uncertainties are obtained from the specifications of instruments. For the calculated parameters, the uncertainties are estimated using the error propagation method proposed by Moffat [42]. Basically, given R is the indirect calculated parameter that can be calculated from several independent directly measured parameters $x_{i}$, as represented by:

$$
R=f\left(x_{1}, x_{2}, \ldots, x_{n}\right)
$$

Then, the propagated error $\delta_{R}$ as determined by the measurement accuracy of each independent primary parameter $\delta_{X i}$ can be expressed by a root-sum-square method:

$$
\delta_{R}=\left\{\sum_{1}^{N}\left(\frac{\partial R}{\partial X i} \delta_{X i}\right)^{2}\right\}^{1 / 2}
$$

Table 3

Uncertainty of measured and calculated parameters.

\begin{tabular}{lllc}
\hline Measured parameter & Uncertainty & Calculated parameter & Uncertainty \\
\hline Channel width $W_{c h}, \mu \mathrm{m}$ & $\pm 5 \mu \mathrm{m}$ & Hydraulic diameter, $d_{h}, \mu \mathrm{m}$ & $\pm 5 \mu \mathrm{m}$ \\
Channel height, $H, \mu \mathrm{m}$ & $\pm 20 \mu \mathrm{m}$ & Mass flux, $G, \mathrm{~kg} / \mathrm{m}^{2} \mathrm{~s}$ & $\pm 2.35 \%$ \\
Volume flow rate, $\dot{V}, \mathrm{~L} / \mathrm{h}$ & $\pm 1 \%$ & Effective heat power, $Q_{e f f}, \mathrm{~W}$ & $\pm 2.69 \%$ \\
Temperature, $T, \mathrm{~K}$ & $\pm 0.3 \mathrm{~K}$ & Heat flux, $q, \mathrm{~W} / \mathrm{cm}^{2}$ & $\pm 1.66 \%$ \\
Pressure, $P, \mathrm{kPa}$ & $\pm 0.1 \%$ & Outlet vapor quality, $x_{e}$ & $\pm 2.9 \%$ \\
Differential pressure, $\Delta P, \mathrm{kPa}$ & $\pm 0.1 \%$ & Cooling efficiency, $\eta_{c}$ & $\pm 3.1 \%$ \\
\hline
\end{tabular}

\section{Results and Discussion}

\subsection{The role of diamond wall conduction}

In this section, we use a finite-volume based numerical method to assess the heat spreading effect of the diamond wall. A full-scale three-dimensional solid heat conduction 
model of the present heat sink, is built up in the ANSYS FLUENT 18.2 solver. The geometry of the numerical prototype is identical to what being experimentally tested. According to the experimental condition, a localized high-density heat flux of $q_{\max }=267 \mathrm{~W} / \mathrm{cm}^{2}$, is imposed on the bottom of heat sink, acting as the heat sources. The trickiest part is the definition of the thermal boundary condition at the V-channel walls. In reality, complex flow evaporation may occur in the channels, so that the heat transfer coefficient along the channel wall may differ from one region to another. Therefore, it is impossible to map the real heat transfer coefficient profile to the channel walls. For the convenience of our tests, we assume the heat transfer coefficient at everywhere of the channel walls is a constant. This assumption, of course, disrespect to the true physical condition of flow boiling. However, it enables us easily evaluate the heat conduction effect of the diamond walls in subject to different cooling condition. We shall hence assign a Neumann boundary condition to the channel walls, which is written as $q_{w}=h\left(T_{w}-T_{\text {sat }}\right)$, where $q_{w}$ is the heat flux at the wall, $h$ is the convective heat transfer coefficient, $T_{w}$ is the wall temperature. This boundary condition roughly represents the cooling effects due to the fluid flow in the channel. The rest of the solid boundaries of the domain are adiabatic. With the given boundary conditions above, the three-dimensional steady heat conduction equation $\nabla(k \nabla T)=0$ can be solved.

For flow evaporation in microchannels, the heat transfer coefficient $h$ is usually at the magnitude of $10^{4}$ to $10^{5} \mathrm{~W} / \mathrm{m}^{2} \mathrm{~K}$. We hence prescribe two different heat transfer coefficients of $10^{4}$ and $10^{5} \mathrm{~W} / \mathrm{m}^{2} \mathrm{~K}$, respectively, to see how the heat transfer in the diamond substrate is influenced. The steady solutions are shown in Fig. . Fig. (a) and (b) suggest the substrate can be cooled more effectively with increasing the heat transfer coefficient. The peak temperature 
always appears at the middle regions where the heat load is directly imposed. The ratio of the wall heat flux at the channel surface relative to the maximum imposed heat flux underneath the heat sink, are presented in Fig. (c) and (d). It can be seen that the heat flux is remarkably redistributed when it is conducted to the surface of channel-walls due to the transverse wall conduction. Owning to this redistribution effect, the heat flux on the channel wall is greatly reduced down to less than $14 \%$ of the maximum imposed heat flux $q_{\max }$. It is this significant heat flux redistribution effect that leads to dramatic reduction of peak temperature in the solid. With increase of the heat transfer coefficient, the redistribution effect would be less significant because of the decrease of the convective heat resistance. Fig. shows qualitatively the heat flux percentage within the directly heated zone (white wireframe in Fig. (c-d)) as the heat transfer coefficient is increased. It is shown that the percentage of the heat flux concentrated in the directly heated zone, is increased with heat transfer coefficient when $h<10^{9} \mathrm{~W} / \mathrm{m}^{2} \mathrm{~K}$, whereas, above $10^{9} \mathrm{~W} / \mathrm{m}^{2} \mathrm{~K}$, the heat flux percentage is no longer increased and remain constant at $73.36 \%$. This is because the convective heat resistance is approximate to zero when heat transfer coefficient is infinite large. In this case, the heat redistribution purely depends on the conductive heat resistances in longitudinal and transversal directions, and the wall temperature could not be further cooled down as shown in Fig. . This is attributed to the inherently existence of conductive heat resistance in the diamond substrate. This means the heat sink has a maximum cooling capacity that could control the mean temperature where is on the base of directly heated region as low as $T_{c}$, and it is impossible to approach the saturation temperature of the refrigerant $T_{s a t}$. Therefore, $T_{c}$ corresponds to the maximum cooling capacity the system could achieve. For this reason, we define the cooling efficiency of 
the current system as:

$$
\eta_{c}=\frac{T_{c}-T_{\text {sat }}}{T_{b}-T_{\text {sat }}}
$$

The theoretical minimum base temperature $T_{C}$ for different experimental conditions can be obtained using the following equation.

$$
T_{C}=R_{C} \times q \times 73.36 \%+T_{\text {sat }}
$$

where $q$ and $T_{\text {sat }}$ represent the imposed heat flux that refers to the directly heated area and the fluid temperature (saturation state), both of which are obtained from experimental data, $R_{C}$ is the normal conductive heat resistance of the diamond substrate, which is determined to be $1.2494 * 10^{-6} \mathrm{~m}^{2} \mathrm{~K} / \mathrm{W}$; and the constant value of $73.36 \%$ is the theoretical maximum percentage of the heat flux concentrated in the directly heated zone. Both the value of conductive heat resistance and the heat flux concentrated percentage are obtained from numerical calculations.

Regarding the experimental research under nonuniform heat flux, the wall temperature $T_{w}$ cannot be simply calculated based on the one-dimensional heat conduction equation, so the heat transfer coefficient cannot be obtained. Therefore, most of the previous studies that are relevant to the present work $[11,13,14]$ directly presented the measured wall temperature as the indicator of the cooling performance of heat sinks at given conditions. The wall temperature, however, reflects the conjugated effects of both fluid convection and wall conduction on the cooling performance. In this study, the cooling efficiency is defined to represent the effect of fluid evaporation on the cooling performance while isolating the wall conduction effect. A larger value of $\eta_{c}$ indicates a higher heat transfer coefficient. Therefore, using this dimensionless parameter is more reasonable than simply presenting the measured wall temperature. We will use this parameter to represent the cooling performance of the system.

Recalling Fig., we shall also see that the percentage of heat flux concentration, in the 
range of $10^{4}<\mathrm{h}<10^{5} \mathrm{~W} / \mathrm{m}^{2} \mathrm{~K}$, is only $24-50 \%$, which means a large portion of the heat flux spreads out of the directly heated region, and should be carried away by the fluid convection in the rest region of the channel. This then reflects the contribution of the wall conduction to the cooling performance of the heat sink.
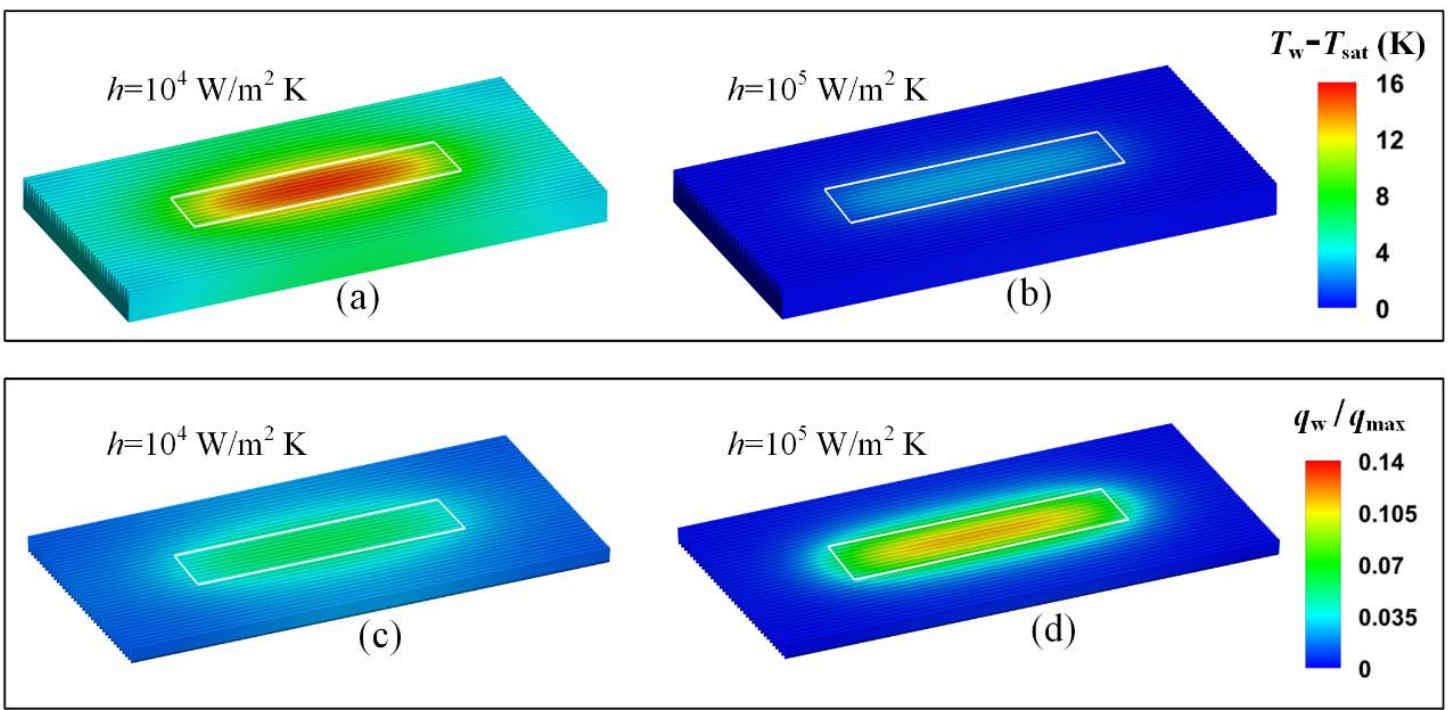

Fig. 6. The influence of wall conduction on the heat flux redistribution. The white wireframe indicates the region, underneath of which the heat load is imposed. (a) and (b) show the temperature distribution in the diamond substrate. (c) and (d) show the heat flux over the surface of the channel walls.

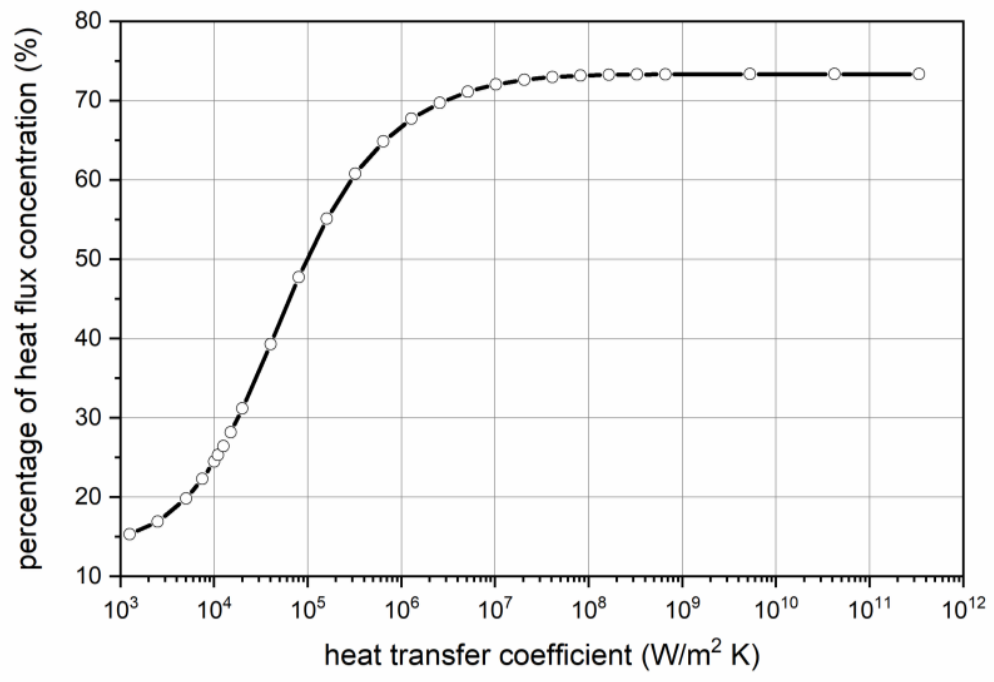

Fig. 7. The dependence of heat flux concentration in the directly heated region on the heat transfer coefficient over the channel walls. 


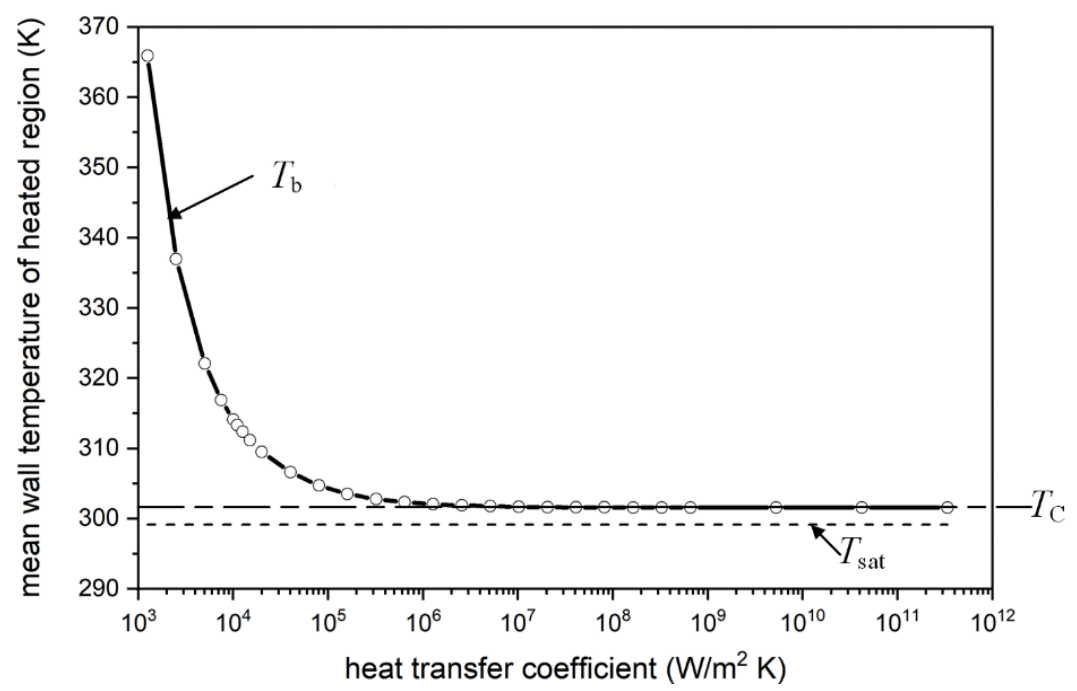

Fig. 8. The dependence of base temperature in the directly heated region on the heat transfer coefficient.

\subsection{The influence of heat flux}

In our experiments, the saturation temperature is always maintained around $26{ }^{\circ} \mathrm{C}$ by controlling the reservoir pressure. For all experimental conditions in the present work, inlet subcooling is kept within $1.3^{\circ} \mathrm{C}$, which can be regarded as an approximate saturated inlet condition. As shown in Fig., for example, the fluid temperature at the inlet and outlet of microchannel heat sink are maintained at $26^{\circ} \mathrm{C}$ for heat flux of $267 \mathrm{~W} / \mathrm{cm}^{2}$ and mass flux of $320 \mathrm{~kg} / \mathrm{m}^{2} \mathrm{~s}$. Moreover, all measured parameters are time-averaged to rule out the influence of the data fluctuation in steady-state maintained about 15 minutes. 


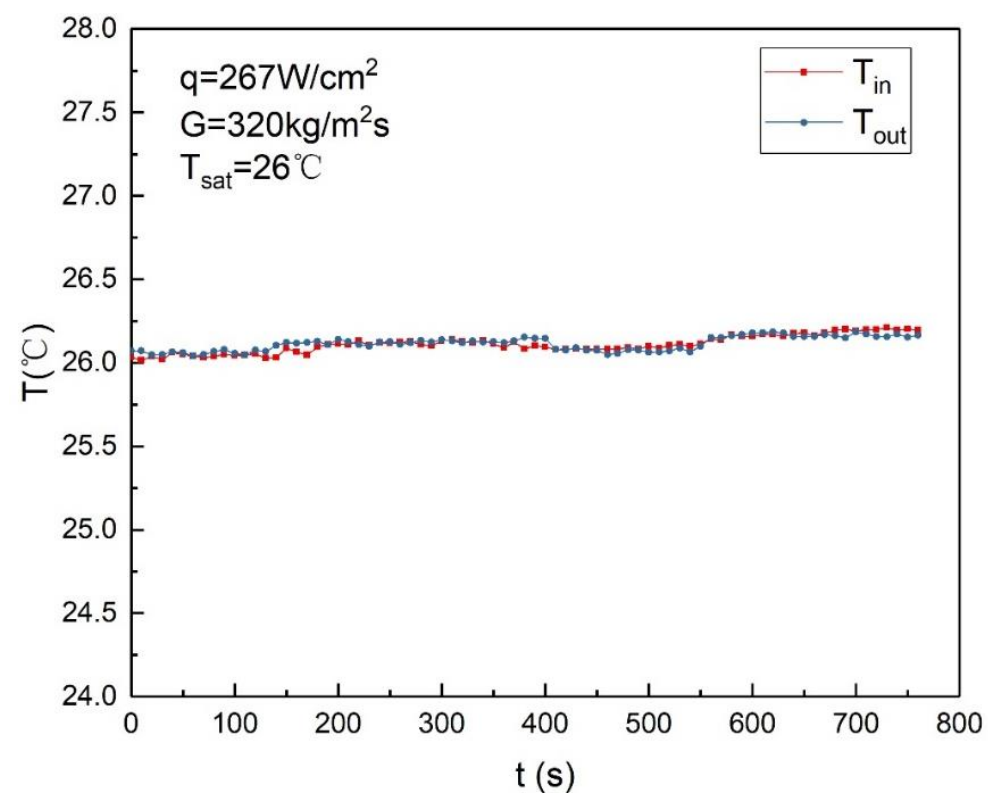

Fig. 9. Fluid temperatures at the inlet and outlet of the heat sink.

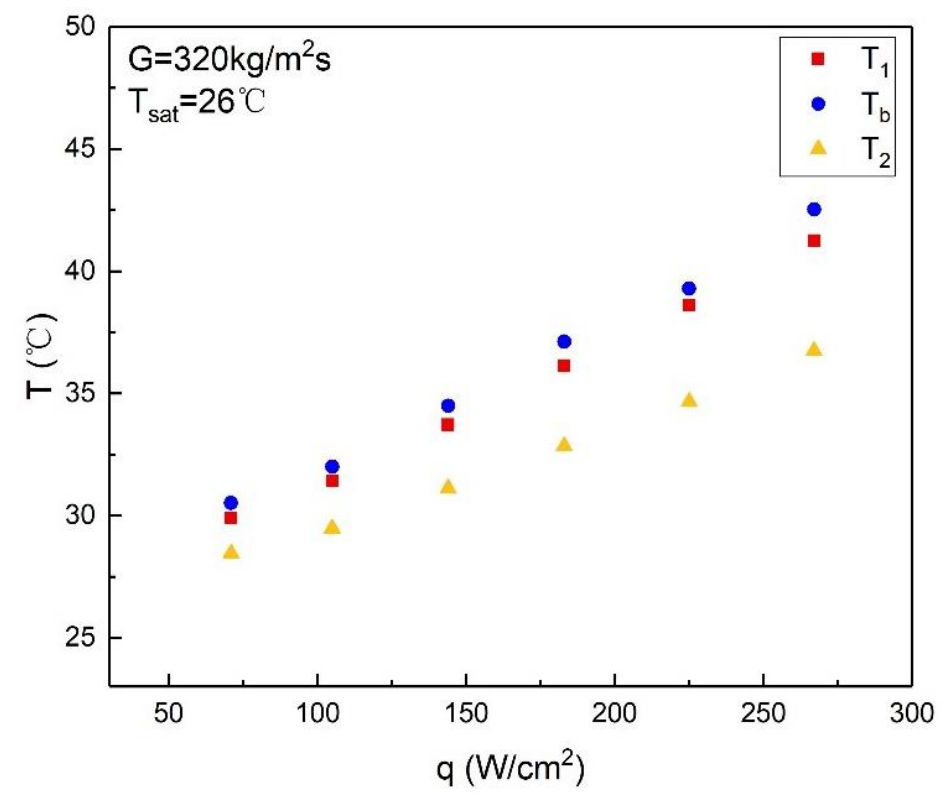

Fig. 10. Temperature distribution on the base surface of the heat sink.

Along the flow direction, $\mathrm{T}_{1}$ and $\mathrm{T}_{2}$ represent the temperatures adjacent to the front and rear of the directly heated area on the heat sink base surface, respectively. $T_{b}$ is the temperature at the midpoint of directly heated area on the heat sink base surface. Fig. shows the temperature distribution at a constant mass flux of $320 \mathrm{~kg} / \mathrm{m}^{2} \mathrm{~s}$. The central hotspot imposes high heat flux on the location of $\mathrm{T}_{\mathrm{b}}$, resulting to a higher value of $\mathrm{T}_{\mathrm{b}}$ than $\mathrm{T}_{1}$ and $\mathrm{T}_{2}$. Moreover, a high degree of superheat is required for the onset of nucleate boiling at the entrance region 
of the heat sink, and the heat transfer performance in this region is inferior to that of the saturated boiling region, which consequently makes $T_{1}$ higher than $T_{2}$. As the heat flux increases from 71 to $267 \mathrm{~W} / \mathrm{cm}^{2}$, the temperatures on the heat sink base surface increase for about $12{ }^{\circ} \mathrm{C}$

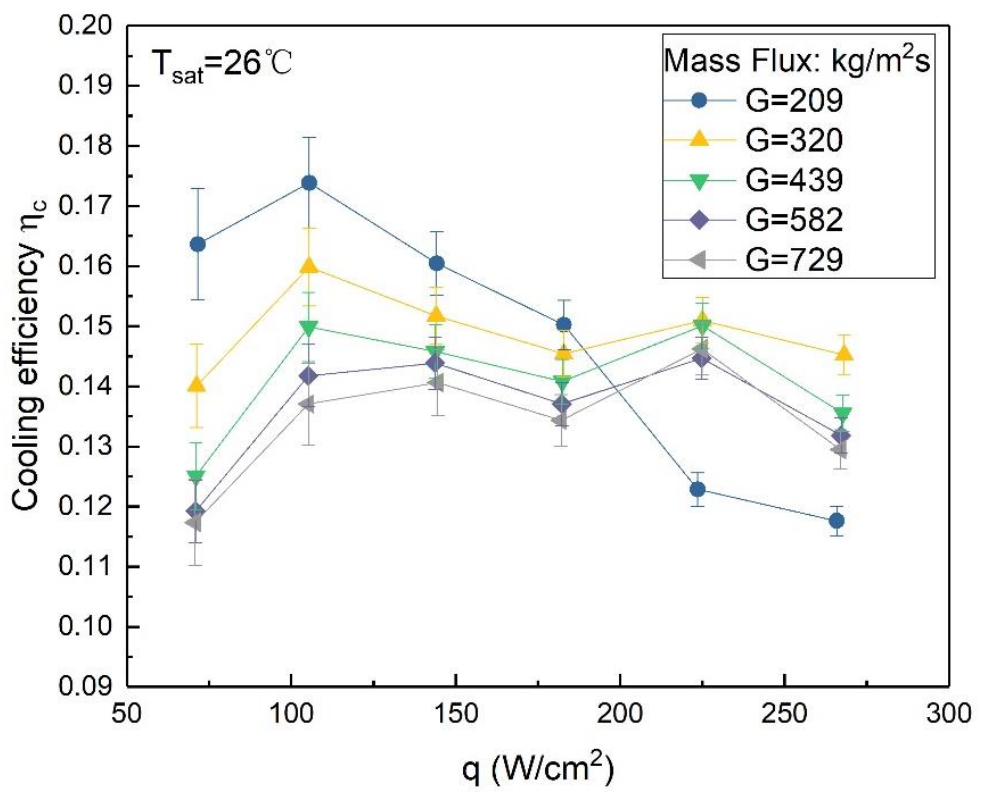

Fig. 4. Variation of cooling efficiency with heat flux at various mass fluxes.

Fig. 4 presents the variation of cooling efficiency with increasing heat flux under various mass fluxes. The cooling efficiency varies between 0.11 and 0.18 under various experimental conditions, and the four curves under various mass fluxes ranging from 320 to $729 \mathrm{~kg} / \mathrm{m}^{2} \mathrm{~s}$ all present a similar M-shaped variation with heat flux. The cooling efficiency increase with heat flux until an inflection point at a heat flux of $105 \mathrm{~W} / \mathrm{cm}^{2}$, then fall toward a plateau-like region between 183 and $267 \mathrm{~W} / \mathrm{cm}^{2}$, within which the fluctuation of cooling efficiency tends to decrease.

The variation characteristics of the cooling efficiency is indicative of the inherent complex flow boiling thermodynamics in microchannels under a central hotspot. At low values of heat flux, the nucleate boiling mechanism is probably dominant, thus the increase of heat flux 
accelerates the nucleation of bubbles and enhances heat transfer remarkably. While as heat flux rises further, bubbles expand along the microchannel, merge together and finally evolve into elongated bubbles due to the limitation of the microchannel geometry. The appearance of elongated bubbles deteriorates the heat transfer performance, which may contribute to the decrease of the cooling efficiency after the first inflection point of the M-shaped curve. With the further increase of heat flux, the chaotic churn flow and severe maldistribution of mass flux in microchannels may occur before stable annular flow is reached, resulting to unstable heat transfer performance.

Particularly, for the lowest mass flux of $209 \mathrm{~kg} / \mathrm{m}^{2} \mathrm{~s}$, the cooling efficiency shows a different trend, decreasing continuously with heat flux after the inflection point, which can be tentatively explained by detrimental impact of partial dryout.

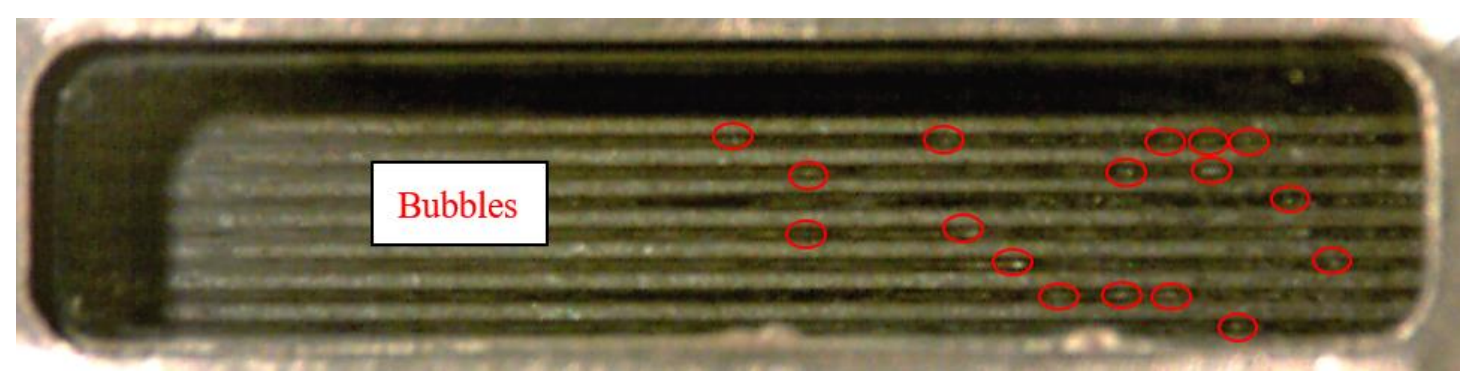

(a)

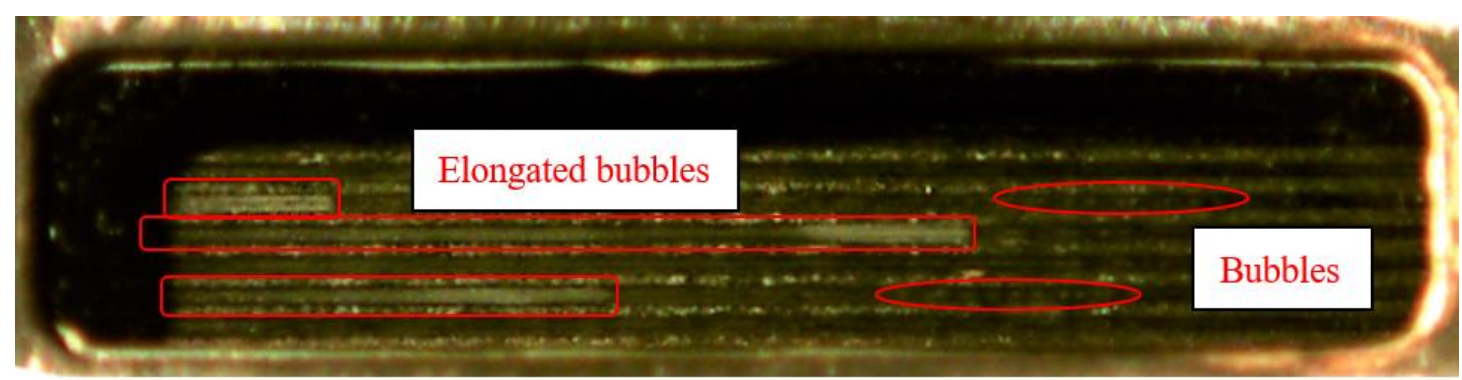

(b)

Fig. 5. Visualization results of flow boiling in microchannels $\left(\mathrm{G}=582 \mathrm{~kg} / \mathrm{m}^{2} \mathrm{~s}\right)$,

$$
\text { (a) } \mathrm{q}=105 \mathrm{~W} / \mathrm{cm}^{2} \text {; (b) } \mathrm{q}=144 \mathrm{~W} / \mathrm{cm}^{2} \text {. }
$$

The visualization results of flow boiling in microchannels under a central hotspot are 
shown in Fig. 5. It should be noted that the images only capture the view of direct heated microchannels. Fig. 5(a) shows that numerous bubbles nucleate on the wall of microchannels at a heat flux of $105 \mathrm{~W} / \mathrm{cm}^{2}$ and mass flux of $582 \mathrm{~kg} / \mathrm{m}^{2} \mathrm{~s}$. In Fig. 5(b), elongated bubbles are found in several microchannels at a higher heat flux of $144 \mathrm{~W} / \mathrm{cm}^{2}$. The transition from bubbly flow to partial elongated bubble flow occurred may contribute to variation of the cooling efficiency in the direct heated microchannels.

\subsection{The influence of mass flux}

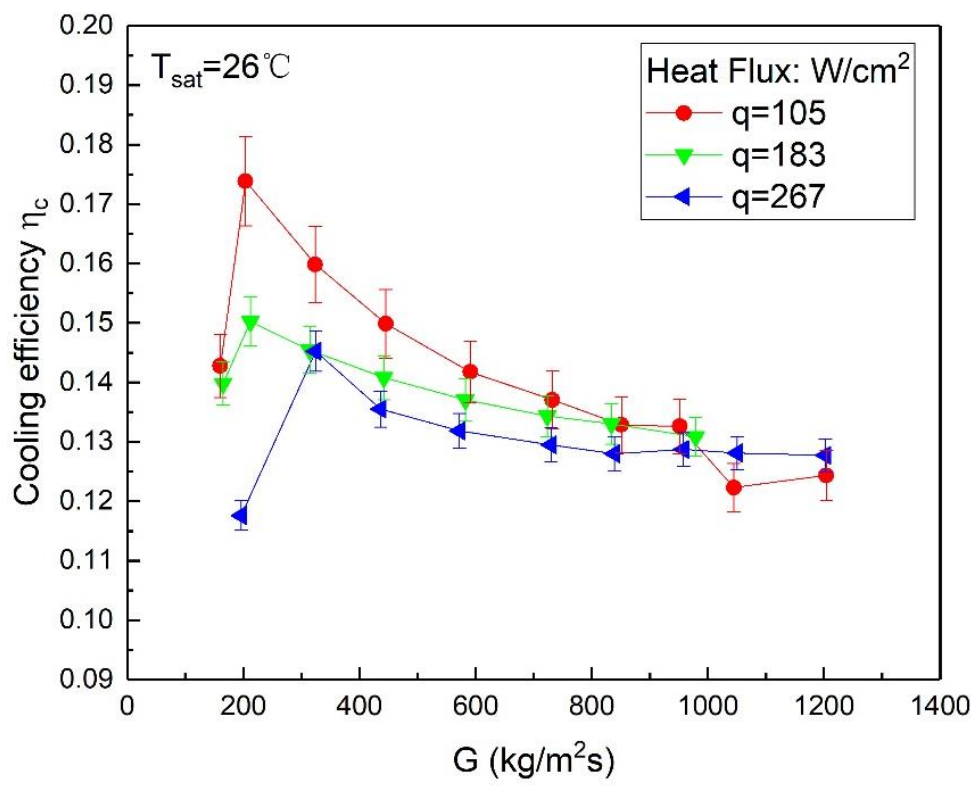

Fig. 6. Variation of cooling efficiency with mass flux at various heat fluxes.

The influence of mass flux on the cooling efficiency of the heat sink for various heat fluxes is illustrated in Fig. 6. The three curves under different heat fluxes show a similar trend. The cooling efficiency rise steeply with increasing mass flux until a peak cooling efficiency of $0.174,0.150$, and 0.145 for a heat flux of 105,183 , and $267 \mathrm{~W} / \mathrm{cm}^{2}$, respectively. The existence of the peak cooling efficiency may be due to the nucleate boiling being most profound at the corresponding mass flux. Before the peak point, the low cooling efficiency is likely indicative of the appearance of elongated bubble flow and partial dryout in microchannels. After the peak 
point, the cooling efficiency decreases with increasing mass flux toward a relatively flat region. Although this phenomenon seems contrary to the principle of convective heat transfer, it is however plausible for two-phase flow boiling because of the combined effects of convective heat transfer and nucleate boiling. For a higher mass flux, the nucleate boiling seems to be suppressed, which outweighs the increase in the convective heat transfer. As a result, the total heat transfer decreases as the mass flux increasing, acting in a similar way reported by Agostini et al. [43].

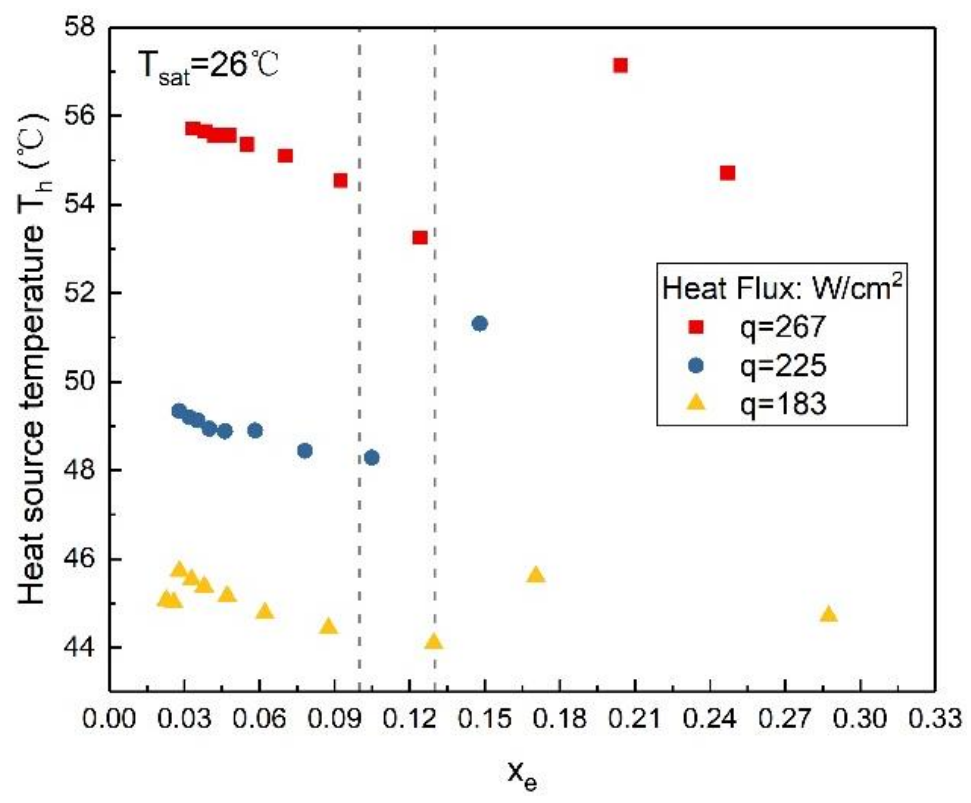

Fig. 7. Variation in the heat source temperature with the outlet vapor quality at various heat fluxes.

Apart from cooling efficiency, the cooling performance of the heat sink can also be directly quantified by the heat source temperature, which is an important indicator concerned in practical application. Fig. 7 depicts the variation in the heat source temperature with the outlet vapor quality for a high heat flux of 183,225 , and $267 \mathrm{~W} / \mathrm{cm}^{2}$ and saturation temperature of $26^{\circ} \mathrm{C}$. Obviously, the heat source temperature increases with the heat flux, while for a heat flux up to $267 \mathrm{~W} / \mathrm{cm}^{2}$, the heat source temperature remains below $58{ }^{\circ} \mathrm{C}$, which indicates the prominent cooling performance of the heat sink. According to the three sets of experiments 
under nonuniform high heat flux, an optimal range of outlet vapor quality from 0.10 to 0.13 is found, within which the minimum heat source temperature can be achieved. For example, for a heat flux of $267 \mathrm{~W} / \mathrm{cm}^{2}$, the heat source temperature can be maintained at $53.3{ }^{\circ} \mathrm{C}$ when the outlet vapor quality is set at 0.124 , and this temperature can be further decreased with a lower saturation temperature.

\section{Conclusions}

In this paper, we experimentally measured the cooling performance of a diamond made heat sink, with the saturated ammonia boiling undergoes in the V-shape channels. In subject to localized heat flux as high as $267 \mathrm{~W} / \mathrm{cm}^{2}$, favorable cooling performance is achieved. The high efficiency is attribute to two aspects of the design. Firstly, the diamond substrate could spread the heat flux transversely, and consequently, the heat flux at the channel wall is dramatically relaxed to a very low level. Secondly, the convective boiling of the ammonia has a relative high heat transfer coefficient at the microchannel walls, enabling the heat flux removed effectively. These combined effects promote the cooling capacity of the heat sink dramatically, which are promising to manage even higher heat load.

\section{Acknowledgements}

This research did not receive any specific grant from funding agencies in the public, commercial, or not-for-profit sectors.

\section{References}

[1] J. Schleeh, J. Mateos, I. Íñiguez-de-la-Torre, Phonon black-body radiation limit for heat dissipation in electronics, Nature Materials. 14 (2014) 187.

[2] M.R.O. Panão, A.L.N. Moreira, D.F.G. Durão, Thermal-fluid assessment of multijet atomization for spray cooling applications, Energy. 36 (2011) 2302-2311. 
[3] W.L. Cheng, F.Y. Han, Q.N. Liu, Experimental and theoretical investigation of surface temperature non-uniformity of spray cooling, Energy. 36 (2011) 249-257.

[4] M.A. Ebadian, C.X. Lin, A Review of High-Heat-Flux Heat Removal Technologies, Journal of Heat Transfer. 133 (2011).

[5] B. Agostini, M. Fabbri, J.E. Park, State of the Art of High Heat Flux Cooling Technologies, Heat Transfer Engineering. 28 (2007) 258-281.

[6] R. Revellin, J.R. Thome, A theoretical model for the prediction of the critical heat flux in heated microchannels, International Journal of Heat and Mass Transfer. 51 (2008) 1216-1225.

[7] R. Revellin, J.M. Quiben, J. Bonjour, Effect of Local Hot Spots on the Maximum Dissipation Rates During Flow Boiling in a Microchannel, IEEE Transactions on Components and Packaging Technologies. 31 (2008) 407-416.

[8] T. Alam, P.S. Lee, C.R. Yap, A comparative study of flow boiling heat transfer and pressure drop characteristics in microgap and microchannel heat sink and an evaluation of microgap heat sink for hotspot mitigation, International Journal of Heat and Mass Transfer. 58 (2013) 335-347.

[9] S.N. Ritchey, J.A. Weibel, S.V. Garimella, Effects of non-uniform heating on the location and magnitude of critical heat flux in a microchannel heat sink, Micro-Nano Scale Transp. 5 (2014) 95-108.

[10] S.N. Ritchey, J.A. Weibel, S.V. Garimella, Local measurement of flow boiling heat transfer in an array of non-uniformly heated microchannels, International Journal of Heat and Mass Transfer. 71 (2014) 206-216.

[11] D. Bogojevic, K. Sefiane, A.J. Walton, Experimental investigation of nonuniform heating effect on flow boiling instabilities in a microchannel-based heat sink, International Journal of Thermal Sciences. 50 (2011) 309-324.

[12] K. Jae-Mo, J. Linan, A. Bari. Convective boiling in microchannel heat sinks with spatially-varying heat generation, in: Eighth Intersociety Conference on Thermal and Thermomechanical Phenomena in Electronic Systems, 2002, pp. 341-346.

[13] C. Eun Seok, K. Jae-Mo, J. Linan. Experimental study on two-phase heat transfer in microchannel heat sinks with hotspots, in: Ninteenth Annual IEEE 
Semiconductor Thermal Measurement and Management Symposium, 2003, pp. 242-246.

[14] J.L. Miler, R. Flynn, G. Refai-Ahmed, Effects of Transient Heating on TwoPhase Flow Response in Microchannel Heat Exchangers, (2009) 563-569.

[15] G. Aguiar, D. Moreira, G. Ribatski, An Experimental Investigation of Transient Hot Spot Effects on the Heat Transfer During Convective Boiling Inside Microchannels. 2017.

[16] L. Yin, R. Xu, P. Jiang, Subcooled flow boiling of water in a large aspect ratio microchannel, International Journal of Heat and Mass Transfer. 112 (2017) 1081-1089.

[17] B. Markal, O. Aydin, M. Avci, Effect of aspect ratio on saturated flow boiling in microchannels, International Journal of Heat and Mass Transfer. 93 (2016) 130-143.

[18] S. Hong, Y. Tang, Y. Lai, An experimental investigation on effect of channel configuration in ultra-shallow micro multi-channels flow boiling: Heat transfer enhancement and visualized presentation, Experimental Thermal and Fluid Science. 83 (2017) 239-247.

[19] T.-H. Yen, M. Shoji, F. Takemura, Visualization of convective boiling heat transfer in single microchannels with different shaped cross-sections, International Journal of Heat and Mass Transfer. 49 (2006) 3884-3894.

[20] D.F. Sempértegui-Tapia, G. Ribatski, The effect of the cross-sectional geometry on saturated flow boiling heat transfer in horizontal micro-scale channels, Experimental Thermal and Fluid Science. 89 (2017) 98-109.

[21] S. Korniliou, C. Mackenzie-Dover, J.R.E. Christy, Two-dimensional heat transfer coefficients with simultaneous flow visualisations during two-phase flow boiling in a PDMS microchannel, Applied Thermal Engineering. 130 (2018) 624-636.

[22] R. Ajith Krishnan, K.R. Balasubramanian, S. Suresh, The effect of heating area orientation on flow boiling performance in microchannels heat sink under subcooled condition, International Journal of Heat and Mass Transfer. 110 (2017) 276-293.

[23] E.M. Fayyadh, M.M. Mahmoud, K. Sefiane, Flow boiling heat transfer of R134a in multi microchannels, International Journal of Heat and Mass Transfer. 110 (2017) 422436.

[24] A.S. Dalkılıç, C. Özman, K. Sakamatapan, Experimental investigation on the flow boiling of R134a in a multi-microchannel heat sink, International Communications in 
Heat and Mass Transfer. 91 (2018) 125-137.

[25] P. Thiangtham, C. Keepaiboon, P. Kiatpachai, An experimental study on twophase flow patterns and heat transfer characteristics during boiling of R134a flowing through a multi-microchannel heat sink, International Journal of Heat and Mass Transfer. 98 (2016) 390-400.

[26] C.B. Tibiriçá, G. Ribatski, Flow boiling in micro-scale channels - Synthesized literature review, International Journal of Refrigeration. 36 (2013) 301-324.

[27] A. Koşar, Y. Peles, Critical Heat Flux of R-123 in Silicon-Based Microchannels, Journal of Heat Transfer. 129 (2006) 844-851.

[28] M.B. Bowers, I. Mudawar, High flux boiling in low flow rate, low pressure drop mini-channel and micro-channel heat sinks, International Journal of Heat and Mass Transfer. 37 (1994) 321-332.

[29] W. Qu, I. Mudawar, Measurement and correlation of critical heat flux in twophase micro-channel heat sinks, International Journal of Heat and Mass Transfer. 47 (2004) 2045-2059.

[30] B. Agostini, R. Revellin, J.R. Thome, High heat flux flow boiling in silicon multi-microchannels - Part III: Saturated critical heat flux of R236fa and two-phase pressure drops, International Journal of Heat and Mass Transfer. 51 (2008) 5426-5442.

[31] T. Chen, S.V. Garimella, A Study of Critical Heat Flux During Flow Boiling in Microchannel Heat Sinks, Journal of Heat Transfer. 134 (2012).

[32] J.E. Park, J.R. Thome, Critical heat flux in multi-microchannel copper elements with low pressure refrigerants, International Journal of Heat and Mass Transfer. 53 (2010) $110-122$.

[33] L. Gao, S.H. Bhavnani, Experimental study of augmented flow boiling in a dielectric fluid due to backward and forward facing stepped microchannels, International Journal of Heat and Mass Transfer. 124 (2018) 484-490.

[34] A. Iqbal, M. Pandey, A simple methodology to incorporate flashing and variation of thermophysical properties for flow boiling pressure drop in a microchannel, International Journal of Thermal Sciences. 132 (2018) 137-145.

[35] T. Alam, W. Li, W. Chang, A comparative study of flow boiling HFE-7100 in 
silicon nanowire and plainwall microchannels, International Journal of Heat and Mass Transfer. 124 (2018) 829-840.

[36] T.A. Kingston, J.A. Weibel, S.V. Garimella, An experimental method for controlled generation and characterization of microchannel slug flow boiling, International Journal of Heat and Mass Transfer. 106 (2017) 619-628.

[37] H. Huang, J.R. Thome, An experimental study on flow boiling pressure drop in multi-microchannel evaporators with different refrigerants, Experimental Thermal and Fluid Science. 80 (2017) 391-407.

[38] C. Falsetti, H. Jafarpoorchekab, M. Magnini, Two-phase operational maps, pressure drop, and heat transfer for flow boiling of R236fa in a micro-pin fin evaporator, International Journal of Heat and Mass Transfer. 107 (2017) 805-819.

[39] B.S. Field, P. Hrnjak. Adiabatic Two-Phase Pressure Drop of Refrigerants in Small Channels, in: ASME 4th International Conference on Nanochannels, Microchannels, and Minichannels, 2006, pp. 1173-1180.

[40] Y.W. Kuang, W. Wang, J.Y. Miao, Flow boiling of ammonia and flow instabilities in mini-channels, Applied Thermal Engineering. 113 (2017) 831-842.

[41] H. Wang, X. Fang, Evaluation Analysis of Correlations of Flow Boiling Heat Transfer Coefficients Applied to Ammonia, Heat Transfer Engineering. 37 (2015) 32-44.

[42] R.J. Moffat, Describing the uncertainties in experimental results, Experimental Thermal and Fluid Science. 1 (1988) 3-17.

[43] B. Agostini, J.R. Thome, M. Fabbri, High Heat Flux Two-Phase Cooling in Silicon Multimicrochannels, IEEE Transactions on Components and Packaging Technologies. 31 (2008) 691-701. 


\section{Nomenclature}

$A_{C u}$, upper surface area of copper block, $\mathrm{cm}^{2}$

$c_{p, l}$, specific heat capacity, $\mathrm{J} /(\mathrm{Kg} \cdot \mathrm{K})$

$d_{h}$, hydraulic diameter, $\mu \mathrm{m}$

$G$, mass flux, $\mathrm{kg} /\left(\mathrm{m}^{2} \mathrm{~s}\right)$

$H$, channel height, $\mu \mathrm{m}$

$h$, convective heat transfer coefficient, $\mathrm{W} /\left(\mathrm{m}^{2} \mathrm{~K}\right)$

$h_{0}$, equivalent heat transfer coefficient of liquid metal, $\mathrm{W} /\left(\mathrm{m}^{2} \mathrm{~K}\right)$

I, current, A

$k$, thermal conductivity, $\mathrm{W} /(\mathrm{m} \cdot \mathrm{K})$

$L$, channel length, mm

$l_{t}$, normal distance between the thermocouple and the upper surface of copper block, mm

$\dot{m}$, mass flow rate, $\mathrm{kg} / \mathrm{s}$

$P$, pressure, $\mathrm{kPa}$

$\Delta P$, differential pressure, $\mathrm{kPa}$

$Q$, electric heat power, $\mathrm{W}$

$Q_{e f f}$, effective heat power, W

$Q_{\text {loss }}$, heat loss, $\mathrm{W}$

$q$, heat flux, $\mathrm{W} / \mathrm{cm}^{2}$

$T$, temperature, ${ }^{\circ} \mathrm{C}$

$T_{b}$, base temperature, ${ }^{\circ} \mathrm{C}$

$T_{c}$, theoretical minimum base temperature, ${ }^{\circ} \mathrm{C}$ 
$T_{\text {sat }}$, saturation temperature, ${ }^{\circ} \mathrm{C}$

$T_{w}$, wall temperature, ${ }^{\circ} \mathrm{C}$

$\Delta T$, temperature gradient, ${ }^{\circ} \mathrm{C}$

$\mathrm{U}$, voltage, $\mathrm{V}$

$\dot{V}$, volume flow rate, $\mathrm{L} / \mathrm{h}$

$W_{c h}$, channel width, $\mu \mathrm{m}$

$x_{e}$, outlet vapor quality

$\Delta x$, vertical interval of thermocouples, $\mathrm{mm}$

$\mathrm{z}$, axial coordinate along the microchannel, $\mathrm{mm}$

\section{Greek symbols}

$\delta$, thickness of the diamond substrate, $\mathrm{mm}$

$\gamma$, latent heat, $\mathrm{kJ} / \mathrm{kg}$

$\eta_{c}$, cooling efficiency

\section{Subscripts}

$1 \sim 6$, thermocouple labels at different locations

$b$, base surface of the heat sink

in, inlet

out or $e$, outlet

sat, saturation

$w$, inner wall 


\section{Table captions}

Table 1 Summary of experimental studies on flow boiling in microchannels.

Table 2 Physical properties of the diamond heat sink.

Table 3 Uncertainty of measured and calculated parameters. 


\section{Figure captions}

Fig. 1 Schematic diagram of the flow boiling test loop.

Fig. 2 Configuration of the test section.

Fig. 3. Shape of the microchannels from (a) top view and (b) cross-section view.

Fig. 4 Surface roughness of the microchannel inner wall, (a) microscope morphology of the surface and (b) the qualitative measurement of the surface roughness.

Fig. 5 Schematic diagram of the heat transfer direction and thermocouple distribution.

Fig. 6 The influence of wall conduction on the heat flux redistribution.

Fig. 7 The dependence of heat flux concentration in the directly heated region on the heat transfer coefficient over the channel walls.

Fig. 8 The dependence of base temperature in the directly heated region on the heat transfer coefficient.

Fig. 9 Fluid temperatures at the inlet and outlet of the heat sink.

Fig. 10 Temperature distribution on the base surface of the heat sink.

Fig. 11 Variation of cooling efficiency with heat flux at various mass fluxes.

Fig. 12 Visualization results of flow boiling in microchannels $\left(\mathrm{G}=582 \mathrm{~kg} / \mathrm{m}^{2} \mathrm{~s}\right)$, (a) $\mathrm{q}=105 \mathrm{~W} / \mathrm{cm}^{2}$; (b) $\mathrm{q}=144 \mathrm{~W} / \mathrm{cm}^{2}$.

Fig. 13 Variation of cooling efficiency with mass flux at various heat fluxes.

Fig. 14 Variation in the heat source temperature with the outlet vapor quality at various heat fluxes. 